\title{
Understanding and Implementing Quality Management System
}

\author{
Sendil Mourougan ${ }^{1}$, Dr. K. Sethuraman ${ }^{2}$ \\ ${ }^{1,2}$ (Department of Business Administration, Annamalai university, India)
}

\begin{abstract}
Hypothesis testing is an important activity of evidence-based research. A well worked up hypothesis is half the answer to the research question. For this, both knowledge of the subject derived from extensive review of the literature and working knowledge of basic statistical concepts are desirable. Thist paper discusses the methods of working up a good hypothesis and statistical concepts of hypothesis testing.
\end{abstract}

Keywords: Effect size, Hypothesis testing, Type I error, Type II error

\section{Introduction}

Despite sharing common elements, previously published ISO management system standards have differed in structure, terminology and requirements, which have inevitably led to confusion and difficulties in implementation particularly when an organization has opted for an integrated management system (IMS) approach. Annex SL (previously known as ISO Guide 83) overcomes these difficulties by imposing a generic management system structure with a common high level structure, identical core text and common terminology and core definitions for use in all MSS (Management Systems Standards). In future ISO MSS will be aligned and the compatibility of these standards will be enhanced.

For example, many organizations have implemented both ISO 9001and ISO 14001but despite sharing common requirements, these management standards currently differ in terms of definitions and details, which has led to conflicts, duplication, confusion and misunderstanding. The adoption of Annex SL will remedy these issues by aligning future management systems standards so that they will have the same 'look-and-feel'. A major consequence will be the development of integrated management systems that will address multiple disciplines (e.g. quality, environmental, health \& safety, etc.).

Individual MSS will also be able to add additional 'discipline-specific' requirements as required provided that these additions do not affect harmonization or contradict or undermine the intent of the high level structure.

\subsection{Quality Management System}

\section{Quality Management System}

A quality management system (QMS) is a set of policies, processes and procedures required for planning and execution (production/development/service) in the core business area of an organization. (i.e. areas that can impact the organization's ability to meet customer requirements.) ISO 9001:2015 is an example of a Quality Management System. A QMS integrates the various internal processes within the organization and intends to provide a process approach for project execution. A Process Based QMS enables the organizations to identify, measure, control and improve the various core business processes that will ultimately lead to improved business performance.

\subsection{ISO 9000 Family of Standards}

ISO 9001 is the best known of the ISO standards on quality, but there are many other standards that can help to reap the full benefits of a quality management system and put customer satisfaction at the heart of the business.

- ISO 9000 contains detailed explanations of the seven quality management principles in addition to many helpful tips on how to ensure these are reflected in the way the organization work. It also contains many of the terms and definitions used in ISO 9001 and constitutes a useful companion document for building a successful quality management system.

- ISO 9004 provides guidance on how to achieve sustained success with quality management system.

- ISO 19011 gives guidance for performing both internal and external audits.

\subsection{QMS Scope}

The scope of the QMS may include the whole of the organization, specific and identified sections of the organization, or one or more functions across a group of organizations. Note that the scope of the QMS will be explicitly included in the third-party certification and must be explicitly stated by the organization. 
Determining the scope of any organization's QMS involves defining the key activities performed and the types of product and services offered to customers. The scope of the QMS must encompass all daily operations of the organization, particularly those activities required to:

- provide products and services that consistently meet customer and applicable statutory and regulatory requirements (i.e. the processes of the QMS).

- enhance customer satisfaction.

- $\quad$ secure revenue and growth of the business.

The scope of a QMS may cover many different departments and areas, depending on the size and complexity of the organization. For example, many 'corporations' own several businesses and companies, meaning the corporation's business scope is quite large and potentially covers multiple products and markets. Smaller organizations have a smaller QMS scope as they are focused primarily on providing families of products and services for their customers.

There is no 'permissible exclusions clause' as such, but the 'scope requirement' (clause 4.3) mandates that when a requirement cannot be applied this fact must be identified and stated in the form of documented information. Where any requirement cannot be applied, this cannot affect the organization's ability or responsibility to ensure conformity of products and services - in other words all exclusions must be justified!

\subsection{QMS Implementation}

There are many ways an organization can implement a quality management system. In-depth advice is available from a number of different resources, including the publication ISO 9001 for small businesses - What to do, but here are a few tips to get started.

- Tip 1 - Define organization objectives. Why does the organization want to implement the standard?

- Tip 2 - Make sure senior management is on board. It is crucial that everyone - from the top down - is supportive of the initiative and its objectives.

- Tip 3 - Identify the organization's key processes for meeting objectives as well as your customers' needs. Within each of these processes, make sure to understand organization customers' requirements and guarantee that they are met - each and every time. This will form the basis of the QMS.

\section{ISO 9001:2015}

ISO 9001:2015 applies to any organization, regardless of size or industry. ISO 9001:2015 (the most recent version of the standard) is made up of a number of different sections, each concentrating on the requirements involved in different aspects of a quality management system.

- Clause 0-3 - Introduction and scope of the standard

- Clause 4-Context of the organization

- $\quad$ Clause 5 - Leadership

- Clause 6 - Planning

- Clause 7 - Support

- Clause 8 - Operation

- Clause 9 - Performance evaluation

- Clause 10 - Improvement

\subsection{Benefits}

ISO 9001:2015 will help organizations ensure their customers consistently receive high quality products and services, which in turn will bring about many benefits, including satisfied customers, management, and employees - and profits. ISO 9001:2015 specifies the requirements for an effective quality management system and not just blind conformity to requirements. Organizations will discover that using the new standard will help them:

- Organize their processes in a logical manner that reflects their operational and business practice.

- Improve the efficiency of processes through the application of risk-based thinking and the PDCA cycle.

- Continually improve performance and effectiveness through the use of quality objectives and process-level KPIs.

- Rationalize and drastically reduce the volume of QMS documentation through the adoption of a processbased approach and the use of modern visual aids.

- Create satisfied customers, management, and employees and encourage a business environment where collaboration is the name of the game. 


\subsection{High Level Structure}

As a result of the new arrangement in ten clauses, ISO 9001:2015 now has the same unambiguous structure as all standardized management systems, known as a 'High Level Structure' (HLS). The core elements of ISO 9001, ISO 14001, ISO 22000, OHSAS 18001, etc. are therefore all the same from now on as shown in Figure 1. This has made the integration of various management systems much simpler. If, for example, an organization wishes to implement ISO 14001 in addition to ISO 9001, the parts that cover the same topic can easily be seen in the standards.

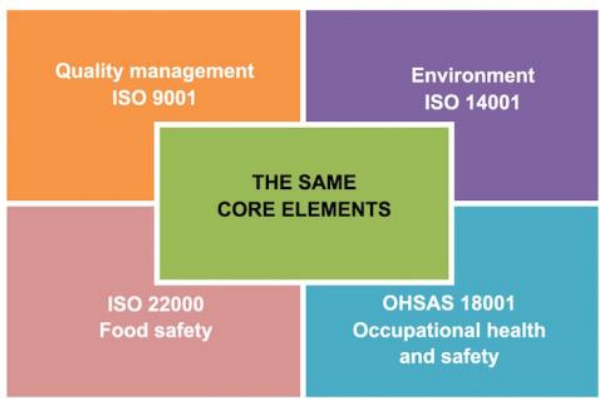

Figure 1. Integration of MSS using core elements

The structure of ISO 9001:2015 will adopt the Annex SL template mandated for all 'discipline-specific' standards which consist of:

- High level structure

- Identical core text

- Common terms and core definitions

The HLS (high level structure) consists of the following clause sequence:

0 . Introduction

0.1 General

0.2 The ISO standards for quality management

0.3 Process approach

0.4 Plan-Do-Check-Act (PDCA) cycle

0.5 'Risk-based thinking'

0.6 Compatibility with other management system standards

1. Scope

2. Normative references

3. Terms and definitions

4. Context of the organization

6. Planning

7. Support

8. Operation

9. Performance evaluation

10. Improvement

- Annex A (informative) clarification of new structure, terminology and concepts

- Annex B (informative) quality management principles

- Annex C (informative) the ISO 10000 portfolio of quality management standards

- Bibliography.

The HLS will enhance the consistency and alignment of different management system standards (e.g. ISO 9001 and ISO 14001). The MSS requirements are contained in clauses four through to ten which include some 45 'shall statements' giving rise to 84 mandatory requirements. These are considered to be the minimum requirements so 'the disciplines' (e.g. aerospace/defence, automotive/motorsport, rail, nuclear, etc.) will add in their own needs, which will result in more sector-specific requirements.

\subsection{ISO 9001:2015 puts more focus on Input and Output}

There is more emphasis in ISO 9001:2015 on measuring and properly assessing the input and output of processes as shown in Figure 2. According to ISO 9001:2015, organization must closely monitor which articles, information and specifications are involved in the production process. It must also clearly check whether good articles come out of the production process. 


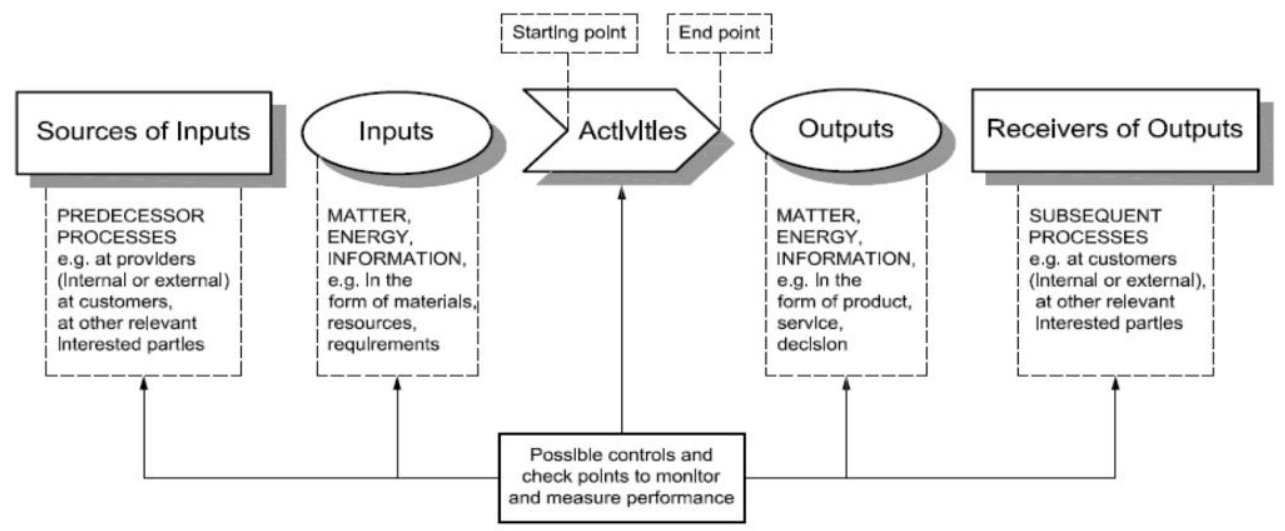

Figure 2. ISO 9001:2015 input-output process

\subsection{Risk-based thinking is at the core of ISO 9001:2015}

Risk-based thinking has a very important place in ISO 9001:2015. Organization are now strongly encouraged to use risk analysis in order to decide for yourself which challenges you see in the management of your business processes. Formal risk analysis, familiar to many organizations via FMEA or HACCP (Hazard analysis and critical control points) techniques, is now standard for everyone. To emphasize their dominance, the concept of 'risk' occurs 48 times in ISO 9001:2015, compared with only three times in ISO 9001:2008. The addition of risk-based thinking has made the 'preventive measures' of ISO 9001:2008 redundant. These preventive measures no longer appear in ISO 9001:2015.

The requirement for preventive action has been replaced by risk-based thinking. This concept is addressed in the ISO 9001:2015 requirements for planning, review and improvement of quality management system processes. Applying risk-based thinking can assist in deciding the type and extent of documented information that is necessary. There is no requirement for formal methods for risk management or a documented risk management process. Consequently organizations can decide whether or not to adopt more extensive risk management approaches, for example the use of:

- SWOT during the analysis of external and internal issues that are relevant to its operations and business.

- P-diagrams, DFMEA and FTA (Fault Tree Analysis) in product design.

- Process-flowcharts and PFMEA during new product introduction focused on production methods.

- Risk register (based on PEST - Political, Economic, Social, and Technological factors) for supplier selection and evaluation.

The benefit of Risk based thinking is multifold. This approach enables organizations to respond to change effectively to protect their business. Organizations will need to start using a risk-driven approach in their organizational processes. A systematic analysis of prioritized risks and opportunities help effective decision making and ensures that the management is prepared to manage and mitigate risks. Plan actions to address the risks, implement the action plan to avoid, eliminate or mitigate risk by taking necessary actions, on time.

This would also help organizations to identify the risks and opportunities depending on the context of an organization and its risk appetite (the amount of risk the organization is willing to accept and live with). There is a proactive approach that helps improve operational efficiency and enables organizations to apply management system to analyze risk and minimize losses. Risk should be assessed for factors those have influence on Quality of Goods and Services and Timeliness on deliver which assures consistency of quality of goods or services and thereby improves customer confidence and satisfaction. Risk-based thinking establishes a proactive culture of improvement. Leadership, a new clause has been introduced in place of Management Responsibility.

\subsection{Organizational Knowledge}

Knowledge has become key to successful operations, new product introduction and business development in general. ISO 9001:2015 considers knowledge like any other resource and it must be acquired and managed. An organization must identify the knowledge necessary to carry out its operational and business activities in compliance with the QMS and to achieve the defined objectives. Such knowledge can be based on internal sources (methoding, simulations, work instructions, technique cards, results of corrective actions, customer feedback, and so on) and external sources (universities, professional bodies, technical standards, conferences, consulting organizations, and so on). Once acquired, it must be maintained, protected and made available where necessary. 
The organization must anticipate changes in knowledge needs and manage the risk of failing to acquire knowledge in due time. Whatever the source, organizational knowledge is useful and useable information specific to an organization - it is gained by experience and the proactive search for solution to operational and business challenges. It is information that is used and shared to achieve the organization's objectives.

\subsection{Leadership and the Quality Manager}

Leadership now replaces management responsibility in line with the EFQM model. An organization's top management must now demonstrate that they are actively involved in the operation of the quality management system. The removal of all references to the role of management representative serves to reinforce the need to see the quality management system embedded into routine business operations, rather than operating as an independent system in its own right with its own dedicated management structure.

Although there is no specific requirement for a management representative it is likely that organizations will elect to have a specific member of management oversee the operation of the QMS and have unrestricted access to top management. It is inevitable that 'traditional' quality assurance activities such as calibration control, inspection/test, control of nonconforming product, internal auditing, etc. will remain the province of a quality manager and his/her team. It is very likely that the specific need for a 'quality manager' will remain in the aerospace sector to meet regulatory requirements.

\subsection{Control of Nonconforming Outputs}

The clause 'control of nonconforming outputs' replaces 'control of nonconforming product' and includes nonconforming product or service generated internally, received from an external provider, or identified by a customer. It is likely that an organization will still define their arrangements for:

- defining the responsibility and authority for reviewing and dealing with nonconforming outputs and the process for approving persons making these decisions.

- taking actions necessary to contain the effect of the nonconformity on other processes, products or services.

- defining corrective actions for nonconforming products and services detected after delivery, as appropriate to their impacts.

In addition, the contractual arrangements for the acceptance of nonconforming products by means of concessions and the disposition of scrapped products must also be addressed.

\subsection{Context of the Organization}

ISO 9001:2015 requires an organization to construct its quality management system from now on from the specific context within which it is active. This means, among other things, organization has to take into account the needs and expectations of interested parties and evaluate and deal with internal and external strategic questions. Organization should understand and respond to the expectations of all the parties concerned.

A new clause (clause 4.1) is introduced relating to the organisation and its context, which requires organizations to determine the issues and requirements that can impact on the planning and development of the management system. This should be a welcomed addition as it provides the opportunity to define the business what is achieved for customers (i.e. the purpose) and the direction in which the organization is heading (i.e. its strategic direction). A common approach to defining the purpose of an organisation, is to agree on:

- Mission: the organization's purpose and reason for existing. Mission concentrates on the present. A mission statement defines the fundamental purpose of an organization. It identifies who the organization is, what it does, and to whom it serves. The mission statement should communicate the scope and scale of the organization's operations, in an easily understandable manner. It describes what the organization does with particular focus on what it does for its customers and other interested parties. It states clearly and concisely the business strategy, and provides personnel with a framework and purpose. Its purpose is to motivate its people, suppliers and other partners.

- Vision: where the organization is going in the medium to long term. Vision focuses on the future. A vision statement is an aspirational description of the desired mid or long term achievements of an organization, by those involved or affected by it. It's what the organization wants to become - how the future will look when the mission is achieved. Its purpose is to motivate external people to work with you. It's the end destination for an organization's 'roadmap': what it hopes to become; the customer outcome it wants achieve; the market position it wants to assume; the impact it will have; the capabilities it plans to develop; and the activities it plans to pursue. When developing its vision, an organization needs to ensure its desired future is consistent with its existing values.

- Values: what the organization stands for - its principles and ethics. Values identify the principles and ethics by which the organization and its members conduct themselves and their activities. Values underpin policies, procedures, strategies, missions and visions by acting as the foundation and a reference point for every decision made by the organization's personnel. 
It can be seen that the above mission, vision and value statements serve to direct and guide an organization over a sustained period of time. Collectively they define the purpose of the organization and should be a high-profile part of the QMS documentation. With the organization's purpose and strategic direction defined, it is required to determine external and internal issues that can impact on their achievement and that also affect its ability to achieve the intended result of its QMS.

A tried and tested approach is to use SWOT analysis which is a framework that helps organizations identify all internal and external issues that might impact their purpose and strategic direction. In a very structured and simple manner, SWOT helps an organization understand the dynamics of everything related to their unique situation. It's directed brainstorming. In the SWOT analytical model, strengths and weaknesses are considered as the internal issues, completely controllable by the organization itself. On the other hand, opportunities and threats are regarded as external issues that might not be controllable by the organization.

The SWOT model states that after thoroughly analyzing every issue in these four categories, an organization should work towards:

- $\quad$ exploiting, managing and developing further their strengths and opportunities.

- $\quad$ eradicating or considerably reducing their weaknesses and external threats.

The results of SWOT analysis can assist in establishing a strategic direction for the organisation. This equates to a conventional business plan, with a span of one to three years. With the purpose and strategic direction defined, attention must be given to understanding the needs and expectations of interested parties, which is addressed in a second new clause (clause 4.2). The key 'focus' is for the organization to:

- consistently provide products and services that meet customer and applicable statutory and regulatory requirements.

- $\quad$ aim to enhance customer satisfaction.

To ensure a 'correct focus', the organization must determine:

- the interested parties that are relevant to the QMS (quality management system).

- the requirements of these interested parties that are relevant to the QMS.

Interested parties can include customers, owners/shareholders, suppliers and partners, people in the organisation that can affect the planning and development of the management system.

\subsection{Engagement of the Interested Parties}

In ISO 9001:2008, customers were often named as being the only interested party. This concept has been extended in ISO 9001:2015. Suppliers, personnel, shareholders, legislative bodies, society, internal customers, etc. are now included as interested parties, in addition to customers. Organizations have to be aware of the importance of these interested parties' (changing) requirements and standards, and anticipate them in the features of your products and services. This has always been part of the standard in another form, however. Therefore, it is not expected that organizations will have to implement major changes in this respect. Organization cannot make or deliver a good product without knowing the requirements and expectations of customers and interested parties in any case. This is the basis of a quality management system.

\subsection{Leadership and Commitment}

ISO 9001:2015 also places more emphasis on leadership and management commitment. It requires greater involvement by top managers and business leaders in controlling the quality management system. This way, ISO 9001:2015 is intended to encourage integration and harmonization with business processes and business strategies. The top management now has to take more responsibility for the effectiveness of the quality management system. Because ISO 9001:2015 pays more attention to risk management, interested parties and the context of the organization, the quality management system also fits in better with the needs of the top management.

The 'management representative' of ISO 9001:2008 was a member of the management committee who had the responsibility and authority for steering the quality management system along the right lines. ISO 9001:2015 does not mention this aspect any more. The idea behind the change is that quality is a matter for everyone and for all levels within the organization.

\subsection{Documented Information}

ISO 9001:2015 no longer requires obligatory documented procedures or a quality manual. This is noteworthy. This is now referred to as 'documented information' in practically all clauses of ISO 9001:2015. The definition states that it concerns 'information that the organization has to control and maintain'. The information can be in any format and come from various sources and media. Diverse forms of evidence or documentation are therefore possible. There is no longer any mention of 'records' neither, but of 'retaining documented information'. 


\subsection{Process Approach}

The adoption of a process approach is now an explicit requirement (clause 4.2.2). For the QMS the 'process approach' should commence with the determination of the key processes needed for communication with customers (enquiries, quotations, sales-order processing, etc.), planning (including new product introduction and production scheduling), supplier control, manufacturing, test and inspection through to packaging/labeling and delivery to the customer. Typical QMS processes could include:

- New customers or major new contracts.

- Enquiries, estimates and quotations.

- NPI (New Product Introduction).

- Design and Development (i.e. product design and development - if applicable).

- Order processing, contract review and production planning.

- Purchasing and SQA (Supplier Quality Assurance).

- Production and/or service provision (i.e. manufacturing and processing).

- Product inspect, test and release certification.

- Customer satisfaction measurement and concerns handling.

- Engineering change management.

Once identified, the organization must ensure that all of its processes are operated under controlled conditions. Controlled conditions require: "ensuring every process is undertaken in exactly the same way, every time and by competent personnel to ensure a consistent result". Visual aids such as SIPOC diagrams and Turtle diagrams can be useful in capturing controlled conditions. As a minimum, controlled conditions include:

- planned activities

- inputs

- outputs

- activities/tasks

- what (with) - i.e. physical resources

- who - i.e. human resources

- how - i.e. procedures, SOPs, work instructions, etc.

- planned results

- management of process-level KPI to ensure that goals/targets are met

- identification of opportunities for improvement of the processes

The fundamental reason for this approach is due to the fact that the standard directs organization towards a process approach in true spirit and control of these processes to produce desired results. Documentation may be necessary to the extent the organization feels necessary and will depend on many factors such as use of Information technology e.g. Enterprise Resource Planning (ERP), Automated process defined controls, competence of people performing task turnover of people, size, complexity, geographical spread and the like.

\subsection{P-D-C-A approach}

Because ISO 9001:2015 employs the process approach, the P-D-C-A (Plan-Do-Check-Act) cycle applies to all identified processes. P-D-C-A enables an organization to ensure that its processes are adequately resourced and managed, and that opportunities for improvement are determined - and acted on. The first three clauses in ISO 9001:2015 are largely the same as those in ISO 9001:2008, but there are considerable differences between ISO 9001:2008 and ISO 9001:2015 from the fourth clause onwards. The last seven clauses are now arranged according to the PDCA cycle (Plan, Do, Check, Act). The following figure 3 shows this. Clauses 4, 5, 6 and 7 of ISO 9001:2015 come under PLAN, clause 8 comes under DO, clause 9 comes under CHECK and clause 10 is covered by ACT. With this new arrangement, the new ISO 9001:2015 strives to give additional momentum to the continuous and systematic improvement of processes within organizations. 


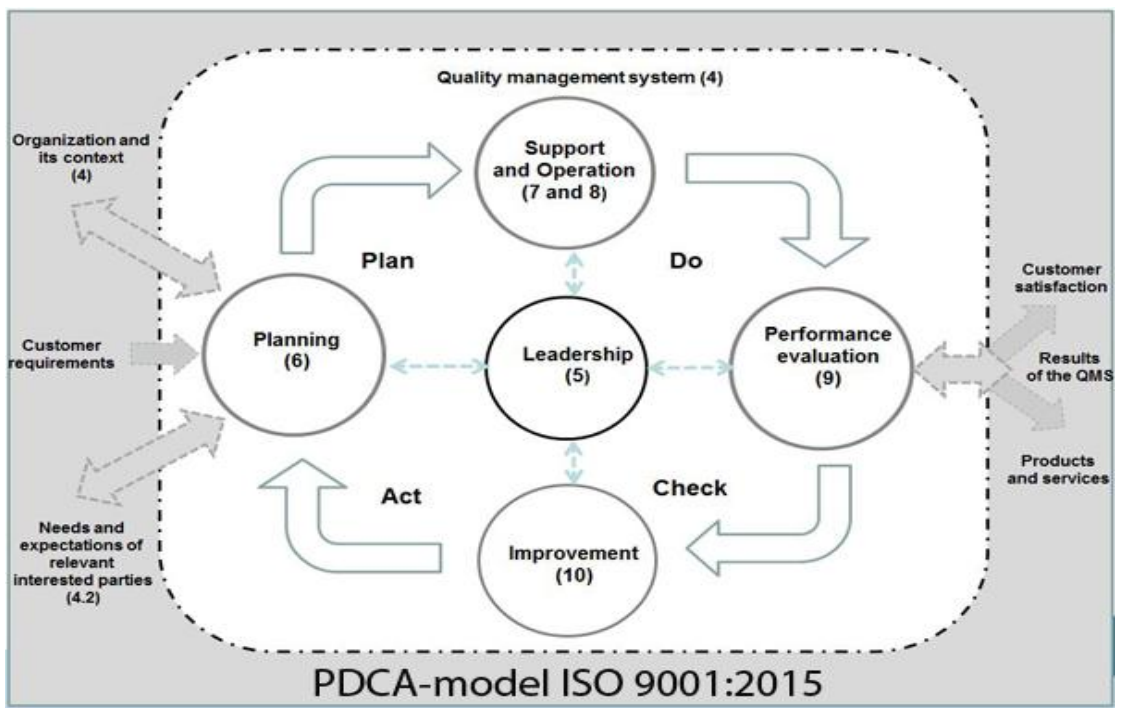

Figure 3. PDCA model of ISO 9001:2015

\section{Quality Management Principles}

ISO 9001:2015 makes more explicit use of the quality management principles. There are now seven the previous principles process approach and system approach to management have been combined. Also, the revision of ISO 9001:2015 has led to a change of one of the principles from continual improvement to just improvement. ISO 9001 builds on seven quality management principles. Following these principles will ensure organization or business is set up to consistently create value for its customers. With these seven pillars firmly in place, implementing a quality management system will be much easier. The seven quality management principles are:

1. Customer focus: Meeting and exceeding customer needs is the primary focus of quality management and will contribute to the long-term success of the organization. It is important to not only attract but also retain the confidence of the customers, so adapting to their future needs is key.

2. Leadership. Having a unified direction or mission that comes from strong leadership is essential to ensure that everyone in the organization understands what they are trying to achieve.

3. Engagement of people. Creating value for the customers will be easier if the organization have competent, empowered and engaged people at all levels of your business or organization.

4. Process approach. Understanding activities as processes that link together and function as a system helps achieve more consistent and predictable results. People, teams and processes do not exist in a vacuum and ensuring everyone is familiar with the organization's activities and how they fit together will ultimately improve efficiency.

5. Improvement. Successful organizations have an ongoing focus on improvement. Reacting to changes in the internal and external environment is necessary if the organisation want to continue to deliver value for the customers. This is of paramount importance today when conditions evolve so quickly.

6. Evidence-based decision making. Making decisions is never easy and naturally involves a degree of uncertainty, but ensuring decisions are based on the analysis and evaluation of data is more likely to produce the desired result.

7. Relationship management. Today's businesses and organizations do not work in a vacuum. Identifying the important relationships with interested parties such as suppliers - and setting out a plan to manage them - will drive sustained success.

\section{ISO 9001:2015 changes}

The following sections address the key changes and provide guidance on implementation strategies. Other approaches may be used provided they meet the requirements of ISO 9001:2015 standard. ISO 9001:2015 has ten clauses instead of eight. The following table shows the relationship of the ISO 9001:2008 clauses to those in the new ISO 9001:2015.

\section{ISO 9001:2008}

0 . Introduction

1. Scope

2. Normative reference

3. Terms and definitions

4. Quality management system

\section{ISO 9001:2015}

0 . Introduction

1. Scope

2. Normative reference

3. Terms and definitions

4. Context of the organisation 
5. Management responsibility

6. Resource management

7. Product realization

8. Measurement, analysis and improvement

\author{
5. Leadership \\ 6. Planning \\ 7. Support \\ 8. Operation \\ 9. Performance evaluation \\ 10. Improvement
}

\subsection{Conceptual Changes}

- Clause 4 requires the organization to determine the risks which can affect its ability to meet the system objectives.

- Clause 5 requires the top management to demonstrate leadership and top management's commitment to ensure that the risks and opportunities that can affect the conformity of a product or service are determined and addressed.

- Clause 6, the organization is required to identify risks and opportunities, and plan how to address the identified risks and opportunities.

- Clause 8 deals with operational planning and control. The organization is required to plan, implement and control its processes.

- Clause 9 requires the organization to monitor, measure, analyze and evaluate the risks and opportunities.

- Clause 10 requires that the organization improves its performance by responding to changes in risk.

\subsection{Clause wise Changes}

ISO 9001:2015 brings quality management and continual improvement into the heart of an organization. The new standard is an opportunity for organizations to align their strategic direction with their quality management system and means that it can be used to help enhance and monitor the performance of an organization. ISO 9001:2015 is based on Annex SL - the new high level structure. This is a common framework for all ISO management systems and helps to keep consistency, align different management system standards, offer matching sub-clauses and apply common language across all standards. There are 10 clauses within the standard and these are the changes:

- Clause 1 is very similar to the 2008 version covering the scope of the standard and there has been very little change to this clause.

- Clauses 2 and 3 cover normative references and term and definitions, both these clauses reference ISO 9000, Quality Management System - Fundamental and vocabulary which provides valuable guidance. The remainder of the clauses includes some new key elements which need to be considered when implementing the new standard.

- Clause 4: Context of the Organization. This is a new clause that establishes the context of the QMS and how the business strategy supports this. The 'context of the organization' is the clause that underpins the rest of the new standard. The organization will need to determine external and internal issues that are relevant to its purpose and would have an impact on what the organization does. Secondly an organization will also need to identify the "interested parties" that are relevant to their QMS. Each organization will identify their own unique set of "interested parties" and over time these may change. Next the scope of the QMS must be determined which should consider any outsourced functions or processes if they are relevant.

- Clause 5: Leadership. This clause places requirements on "top management" which is the person or group of people who directs and controls the organization at the highest level. It is no longer the responsibility of an individual or to have a "Management Representative" who is responsible for the QMS. Top management now have greater involvement in the management system and must ensure the requirements are integrated into the organization's processes and it is compatible with the strategic direction of the organization. The quality policy should be a living document, at the heart of the organization. There is also a greater focus on top management to enhance customer satisfaction by identifying and addressing risks and opportunities that could affect this.

- Clause 6: Planning. Planning has always been a familiar element of ISO 9001, but now there is an increased focus on ensuring that it is considered with Clause 4.1 'context of the organization' and Clause 4.2 'interested parties'. The organization will need to plan actions to address both risks and opportunities, how to integrate and implement the actions into its management system processes and evaluate the effectiveness. Actions must be monitored, managed and communicated across the organization. Another key element of this clause is the need to establish measurable quality objectives. This retains some of the requirements contained in Clause 5.4 of the 2008 version but is more specific.

- Clause 7: Support. Clause 7 ensures there are the right resources, people and infrastructure to meet the organizational goals. Simply expressed, this is a very powerful requirement covering all QMS resource needs and now covers both internal and external resources. Organizational knowledge is a new requirement 
which deals with requirements for competence, awareness, and communication of the QMS. Personnel must not only be aware of the quality policy, but they must also understand how they contribute to it and what the implications of not conforming are. There is a key requirement to maintain the knowledge held by an organization to ensure conformity of products and services. Finally there are the requirements for "documented information". This is a new term, which replaces the references in the 2008 standard to "documents" and "records". Organizations need to determine the level of documented information necessary to control the QMS.

- Clause 8: Operation. This clause deals with the execution of the plans and processes and includes much of what was previously referred to in Clause 7 of the 2008 version. However, there is a greater emphasis on the control of processes especially planned changes and review of the consequences of unintended changes, and mitigating any adverse effects as necessary. The revised version of the standard also acknowledges the trend towards greater use of subcontractors and outsourcing, whose performance should be monitored. There is also a new clause which covers post-delivery activities. This could include activities such as maintenance programs, and activities covering final disposal or recycling of the product.

- Clause 9: Performance Evaluation. Performance evaluation covers many of the areas previously featured in Clause 8 of the 2008 version. Requirements for monitoring, measurement, analysis and evaluation are covered and organizations will need to consider what needs to be measured, methods employed, when data should be analyzed and reported on and at what intervals. There is now an emphasis on directly seeking out information that relates to how customers view the organization. Organizations must actively seek out information on customer perception. There is now an explicit requirement that organizations must show how the analysis and evaluation of this data is used, especially with regards to the need for improvements to the QMS. Internal audits must also be conducted and this is largely unchanged from those in the 2008 version. Management reviews are still required but there are additional requirements including the consideration of changes in external and internal issues that are relevant to the QMS.

- Clause 10: Improvement. The final clause starts with a new section that organizations should determine and identify opportunities for improvement. There is also a need to actively look for opportunities to improve processes, products and services, and the QMS, especially with future customer requirements in mind. Due to the new way of handling preventive actions, there are no preventive action requirements in this clause. However, there are some new corrective action requirements. The requirement for continual improvement has been extended to cover the suitability and adequacy of the QMS as well as its effectiveness, but it no longer specifies how an organization achieves this. In summary, there will be a number of new areas that organizations need to consider when implementing the new standard, but it provides a great opportunity to review your current approach and spring clean where appropriate. This could help your business grow, increase customer satisfaction, and increase profitability. It is now a powerful business improvement tool for organizations of all sizes and in manufacturing or service industries to use to help them remain resilient and achieve sustainable growth.

\subsection{New Terminology}

The following table is a brief summary of a number of important changes to the terminology compared with ISO 9001:2008.

\section{ISO 9001:2008}

Products

Documentation, quality manual,

documented procedures, records, instructions

Work environment

Monitoring and measuring equipment

Purchased product

Supplier

\section{ISO 9001:2015}

Products and services

Documented information

Environment for the operation of processes

Monitoring and measuring resources

Externally provided products and services

External provider

This is not an exhaustive list of the differences between ISO 9001:2008 and ISO 9001:2015, but it does show the main points.

\subsection{Transition from ISO 9001:2008 to ISO 9001:2015}

Organizations are granted a three-year transition period to migrate their quality management system to the new edition of the standard. Assuming that a company is already ISO 9001 certified, the following steps are recommended to comply with ISO 9001:2015: 


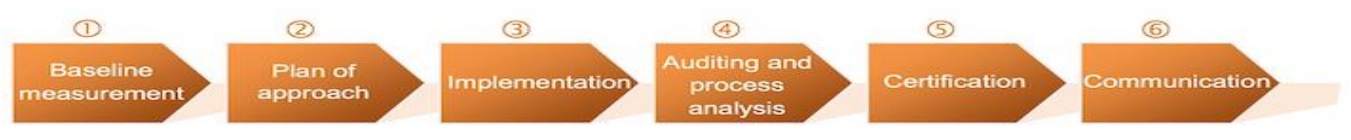

1. Baseline measurement: Perform a baseline measurement of the organization. Make a complete overview of the current status of quality management system and organization's conduct of business.

2. Plan of approach: Draw up a plan based on the baseline measurement. This plan helps to make changes and implement improvements step by step.

3. Implementation: Implement the changes in accordance with the plan of approach. Incorporate measurement points and milestones.

4. Auditing and process analysis: Measure whether the changes have had the desired effect. Measure the input and output of the processes the organization consider to be important because they are critical or risky.

5. Certification: Does the organization certified according to ISO 9001:2015.

6. Communication with interested parties: Show the interested parties not just the certificate, but also show them the results with pride. They should see how well the organization manages its processes and continuously improves them.

\section{Conclusion}

Auditors to handle this change need more maturity, understanding of processes, sector specific knowledge to ensure optimum level of documentation with a focus of process inputs. Activities, controlled condition to produce desired results. Auditors should focus as to- how the process requirements are defined, responsibility, authority and activities, tasks etc. and results with supporting objective evidence. Therefore auditor should not insist or demand a procedure from his experience with other organization. Look at processes, activities, controls, results and whether results meet with objectives. Procedural compliance does not necessarily ensure organization will achieve its objectives. Focus is on consistent result.

\section{References}

[1]. Annex SL (normative) Proposals for management system standards.

[2]. ISO/CD 9001 Quality Management Systems - Requirements.

[3]. ISO/CD 14001 Environmental Management Systems - Requirements.

[4]. ISO/CD 18001 Occupational Health and Safety Management Systems - Requirements.

[5]. ISO/CD 22000 Food Safety Management Systems - Requirements.

[6]. Scrimshire David, 'How to implement ISO 9001:2000 ... to your advantage', Metalworking Production, (May 2001), pp75-78.

[7]. Scrimshire David, 'AS9100 - global takeoff', Quality World, (March 2001), pp30-32.

[8]. Scrimshire David, 'Process map your procedures', Foundryman, ICME journal (May 2001), pp144-146. 